\title{
Comorbidities and Functional Impairment among People Living With HIV in Belém, Pará, Amazon Region of Brazil
}

\section{Ana Helena de Oliveira Andrade ${ }^{1,2}$, Sandra Souza Lima², Andre Luis Ribeiro Ribeiro ${ }^{3}$, Sílvio Augusto Fernandes de Menezes ${ }^{4}$ and Luiz Fernando Almeida Machado ${ }^{1,2 *}$}

${ }^{1}$ Biology of Infectious and Parasitic Agents Post-Graduate Program, Federal University of Pará, Belém, Pará, Brazil

${ }^{2}$ Virology Laboratory, Institute of Biological Sciences, Federal University of Pará, Belem, Pará, Brazil

${ }^{3}$ Department of Oral and Maxillofacial Surgery, School of Dentistry, University Centre of Para-CESUPA, Belem, Pará, Brazil

${ }^{4}$ Department of Periodontology, School of Dentistry, University Centre of Para - CESUPA, Belem, Pará Brazil

*Corresponding author

\section{A B S T R A C T}

\begin{tabular}{|l|}
\hline Ke y w or d s \\
HIV-1, Comorbidity, \\
$\begin{array}{l}\text { Functional impairment, } \\
\text { Functional status }\end{array}$ \\
\hline Article Info \\
\hline $\begin{array}{l}\text { Accepted: } \\
\text { 28 May } 2018 \\
\text { Available Online: } \\
\text { 10 July } 2018\end{array}$ \\
\hline
\end{tabular}

This study has investigated the relationship between clinical parameters and functional status for activities of daily living (ADL) in 364 people living with HIV/AIDS (PLWHA) in Belém, northern Brazil. In total, 238 men (65.4\%) and 126 women (34.6\%) were enrolled in this survey. Most participants (87.4\%) were considered with functional independence, $11.8 \%$ were semi-dependent and $0.8 \%$ were fully dependent. Tuberculosis, neurotoxoplasmosis and syphilis were the most common HIV-associated comorbidities and cumulative comorbidities were linked to lower independence. Low $\mathrm{CD}^{+}{ }^{+}$count and long duration of HIV infection were both related to decreased independence. Women were more affected by low mood/demotivation than men, the last had higher employment rates and more access to higher education, which may have contributed to a better emotional status. We concluded that duration of HIV infection, low $\mathrm{CD}^{+}$count and history of HIVassociated comorbidities affects functional status and compromise the independence of PLWHA.

\section{Introduction}

It is estimated that around 36.9 million people worldwide are infected with the human immunodeficiency virus 1 (HIV-1), and regardless the advances in treatment and preventive politics, this number is still rising [Cobbing et al., 2015; Huang et al., 2015].
The introduction of highly active antiretroviral therapy (HAART) was a watershed in the history of HIV infection and acquired immune deficiency syndrome (AIDS), which significantly increased the survival of people living with HIV/AIDS (PLWHA). Despite it, opportunistic infections and other HIVassociated comorbidities are still very 
common in HIV/AIDS patients, and they are considered a serious problem of public health worldwide [Carvour et al., 2015; Heaton et al., 2010; Mayo et al., 2016; Tan et al., 2012].

PLWHA may experience the loss of functional capacity and physical independence; cognitive decline; anxiety; depression; and impairment in social interaction, self-stem and communication [Mayo et al., 2016; DubÈ et al., 2005].

The concept of functional capacity can be defined as the capability of performing tasks and activities that are necessary or desirable in people's life and required for performing activities of daily living (ADL) in an independent way. ADL include basic routine tasks, such as eating, dressing, walking and performing personal hygiene. [Carioli and Teixeira, 2014; Erlandson et al., 2014].

One way to assess the quality of life (QoL) of people is using evaluation instruments, such as the Functional Independence Measure (FIM). FIM is a well-known assessment tool used to evaluate patients' ${ }^{\prime}$ physical, psychological and social function. The FIM can generate a profile based on the degree of independence of subjects to accomplish several tasks like selfcare, locomotion, sphincter control, communication and social interaction. This tool has been used in studies in Brazil [Machado et al., 2013; Riberto et al., 2004] and other countries in the world to assess patients' disability [Aydin et al., 2016; Vanbellingen et al., 2016].

This study aimed to investigate the degree of functional independence to perform ADL in PLWHA who were assisted in a specialized reference center in Belém, northern Brazil, and to correlate the clinical and epidemiological characteristics of PLWHA with HIV-associated comorbidities and clinical parameters.

\section{Materials and Methods}

\section{Study Design and Sampling}

It was a cross-sectional study in PLWHA who were being assisted in the Centro de Atendimentoem Doenças Infecciosas

Adquiridas (CASA-DIA) in Belém , Pará, Amazonregion of northern Brazil, between June-October 2016. The inclusion criteria were: age between 18 and 54 (working age), confirmed HIV infection, voluntary participation of subjects and signature of the patient informed consent form. The exclusion criteria included patients with severe neurological and cognitive impairment who were unable to answer the questionnaire in an appropriate way.

\section{Sample Size and Ethical Aspects}

Sample size calculation was based on the estimative of individuals enrolledin CASADIA in 2015 (approximately 7,108 patients). The sampling error $(\varepsilon)$ assumed in this calculation was $5 \%$ and the statistical power adopted was $80 \%$, which resulted in a minimum sample size of 364 participants. The objectives of this study were explained to all patients, and those who agreed to participate; signed the patient consent form and answered a structured epidemiological questionnaire (through a guided interview) applied by an occupational therapist. The questionnaire included demographic (age, sex, educational background) and epidemiological information (time of diagnosis of HIV-1 infection, treatment with HAART and aspects of social life). Medical history regarding HIVassociated comorbidities, $\mathrm{CD} 4^{+} \mathrm{T}$ cells $\left(\mathrm{CD} 4^{+}\right)$ counts and plasma HIV-1 viral load was obtained from the medical records. The study was approved by the ethics committee from the Instituto de Ciências da Saúde, Universidade Federal do Pará, under number CAAE 56117616.0.0000.0018. 


\section{Functional Assessment and Medical History}

The functional status of participants was evaluated by means of FIM, which was used to assess the overall performance in ADL, motor and cognitive parameters. The FIM is a validated tool that quantitatively assesses individuals' degree of independence in several areas such as self-care, sphincter control, locomotion, communication and social interaction [Riberto et al., 2004]. All participants were interviewed using a standard questionnaire commonly used to assess ADL and each of the evaluated activities received a score ranging from 1 (total dependence) to 7 (total independence). Data from HIVassociated comorbidities and clinical parameters from blood tests were retrieved from the medical records.

\section{Statistical Analysis}

The clinical-epidemiological and laboratory data were entered into a database using Microsoft Access 2013 software. Frequency tables, percentages, means and standard deviations were used to present the results. The degree of individual independence in relation to duration of HIV infection, history of comorbidities, $\mathrm{CD}^{+}$count, and HIV viral load using the Chi-Square test at a significance level of $5 \%$.

\section{Results and Discussion}

A total of 386 subjects were initially enrolled and after consideration of inclusion/exclusion criteria, 364 individuals were included in this survey. From those participants, 238 (65,4\%) were male and $126(34,6 \%)$ were female. The mean age was 31.4 for men, with the age range of 27-35 being the most prevalent with $42.4 \%$. The average age for females was 7.1 years higher than men(38.5), while the most prevalent age range for women was 36 to 44 $(47 \%)$.
Regarding to marital status, the majority of the participants were single, males $(94.1 \%)$ and females $(77.8 \%)$. The educational background indicated most men (56.7\%) and women (57.9\%) had completed the high school (10 years of formal education or more). Furthermore, $23.9 \%$ of men reported having some level (complete or incomplete) of higher education (13 years of formal education or more). Illiteracy was reported among women only $(1.6 \%)$. The monthly familial income was up to 1 minimum Brazilian wage (equivalent to 252 USD at the time of the study was carried out) for $84.1 \%$ of women and $60.1 \%$ of men, which should take in consideration that the unemployment rate was higher among women $(57.9 \%)$ than in men $(45.0 \%)$.Sociodemographic, HAART treatment, viral load and $\mathrm{CD} 4^{+}$count data are described in Table 1.

In relation to the timing of diagnosis of HIV-1 infection, most men $(69.7 \%)$ and women (63.4\%) were in the interval between 1-5 years of confirmed HIV infection, while $10.9 \%$ of men and $11.9 \%$ of women have had known HIV infection for more than 10 years. Although HAART was abandoned at least once in $21 \%$ of men and $34.2 \%$ of women, most of the individuals were using HAART during the time of the survey, and only $2.1 \%$ of men and $4.8 \%$ of women had not begun the antiretroviral therapy. The $\mathrm{CD} 4^{+}$counts ranged from 101 to 500 cells $/ \mathrm{mm}^{3}$ in $49.2 \%$ in either males and females. The plasma HIV-1 viral load was determined as a $\log 10$ and ranged from <1.69 $\log 10$ to $4.00 \log 10$. A CD4 ${ }^{+}$ count below than $4.00 \log 10$ was considered undetectable. The most prevalent group for men and women had undetectable viral load and women had around $40 \%$ more participants with HIV viral load above 10,000 than men, proportionally (Table 1).

A total of 242 participants (66.5\%) have had at least one HIV-associated comorbidity before this survey, 165 (68.2\%) were male and 
$77(31.8 \%)$ were female, with a slightly higher ratio of comorbidities in men than in women (2.2:1), taking in consideration a higher proportion of men versus women (1.9:1) in this study. The most common HIV-associated comorbidity in male was syphilis (44/165; $26.7 \%)$, whiletuberculosis $(22 / 77 ; 28.6 \%)$ was the most common among women. In male, syphilis, tuberculosis and neurotoxoplasmosis were the most prevalent comorbidities, while in women, the top 3 were the same, but in a different order: tuberculosis, neurotoxoplasmosis and syphilis. Other comorbidities have also been reported at a lower frequency. They were grouped and named as others, which included: rheumatoid arthritis, leprosy, meningitis, epilepsy, mental disorder and malaria (Table 2).

Social life is an important criterion that influence the life of PLWHA, because it not only affects the overall QoL after HIV diagnosis but can also interfere in the adherence to HAART. Most men and women reported to be engaged in social activities, such as going out, social events, family meetings, and friends or community activities. They also reported having support of their friends and family to taking part in these activities and other aspects of life in a similar high proportion of around 83\%. However, despite having similar rates of social life and family/friends support, women were more emotionally affected by HIV infection and experienced significant higher distribution of low mood/demotivation than men $(\mathrm{p}<0.0067)$ (Table 3).

Results from functional independence measures (Table 4) showed that the majority of participants demonstrated to be satisfactory independent to perform ADL, such as personal care (food, hygiene, dressing), locomotion, transportation, communication and cognition. Twenty-four men (10.1\%) and 19 women (15.1\%) were classified as semi-dependent (moderate dependence), with only two men $(0.8 \%)$ and one woman $(0.8 \%)$ being considered as fully dependent, which means they need maximum or total help to carry out their daily activities.

To correlate the functional status (degree of independence) with the presence of comorbidities, duration of HIV infection diagnosis, $\mathrm{CD}^{+}$count and plasma viral load, the participants were divided in two groups: independent and dependent (semi-dependent and fully dependent).

Results showed that the history of HIVassociated comorbidities, duration of HIV infection and low $\mathrm{CD}^{+}$count $(<100)$ were associated with some loss of independence, only the HIV viral load did not significantly affect the level of independence. The participants who never had a history of comorbidities were independent in $95.6 \%$ of the cases, while they experience a growing number of comorbidities, the independence level drops significantly (Table 5). The duration of HIV infection also affected the independence of the participants. During the first year after diagnosis, PLWHA reported to be very independent (94.1\%), but according the time passes, the dependence rate grows to 2.8 times between 1-5 years, 2.3 times between 5-10 years, and 3.8 times after 10 years (Table 5).

Low $\mathrm{CD}^{+}$count $(<100)$ was associated with a higher dependence rate. Individuals who had the $\mathrm{CD}^{+}$count $(<100)$ reported to be dependent in $33.3 \%$ of the cases, while when the $\mathrm{CD}^{+}$count was $>100$, the highest dependence rate was $16.7 \%$, surprisingly found in patients with $\mathrm{CD}^{+}$count $>10,000$ (Table 5).

There is limited information regarding the impact of HIV infection and HIV-associated comorbidities in PLWHA in Brazil. 
Table.1 Socio-demographic and clinical data in PLWHA in Belém, northern Brazil

\begin{tabular}{|c|c|c|c|c|}
\hline \multirow[t]{2}{*}{ Variables } & \multicolumn{2}{|c|}{ Male } & \multicolumn{2}{|c|}{ Female } \\
\hline & $\mathbf{n}$ & $(\%)$ & $\mathbf{n}$ & $(\%)$ \\
\hline \multicolumn{5}{|l|}{ Age } \\
\hline $18-26$ & 44 & 18.5 & 22 & 17.4 \\
\hline $27-35$ & 101 & 42.4 & 38 & 30.2 \\
\hline $36-44$ & 59 & 24.8 & 47 & 37.3 \\
\hline $45-54$ & 34 & 14.3 & 19 & 15.1 \\
\hline \multicolumn{5}{|l|}{ Educational background } \\
\hline Illiteracy & 0 & 0 & 2 & 1.6 \\
\hline Elementary and/or middle school & 46 & 19.4 & 40 & 31.7 \\
\hline High school & 135 & 56.7 & 73 & 58 \\
\hline Higher education & 57 & 23.9 & 11 & 8.7 \\
\hline \multicolumn{5}{|l|}{ Marital status } \\
\hline Single & 224 & 94.1 & 98 & 77.9 \\
\hline Married & 13 & 5.5 & 20 & 15.9 \\
\hline Widowed & 1 & 0.4 & 4 & 3.1 \\
\hline Divorced & 0 & 0 & 4 & 3.1 \\
\hline \multicolumn{5}{|l|}{ Employed } \\
\hline Yes & 131 & 55 & 53 & 42.1 \\
\hline No & 107 & 45 & 73 & 57.9 \\
\hline \multicolumn{5}{|l|}{ Monthly family income $\mathrm{a}^{\mathrm{a}}$} \\
\hline Upto 1 minimum wage & 143 & 60.1 & 106 & 84.1 \\
\hline 1-3 minimum wages & 82 & 34.5 & 19 & 15.1 \\
\hline$>3$ minimum wages & 13 & 5.4 & 1 & 0.8 \\
\hline \multicolumn{5}{|l|}{ Durationof HIV infection } \\
\hline$<1$ year & 53 & 22.3 & 25 & 19.8 \\
\hline 1-5 years & 113 & 47.5 & 55 & 43.7 \\
\hline 5-10 years & 46 & 19.3 & 31 & 24.6 \\
\hline$>10$ years & 26 & 10.9 & 15 & 11.9 \\
\hline \multicolumn{5}{|l|}{ HAART treatment } \\
\hline Yes & 233 & 97.9 & 120 & 95.2 \\
\hline No & 5 & 2.1 & 6 & 4.8 \\
\hline \multicolumn{5}{|l|}{ Duration of HAART } \\
\hline$<1$ year & 68 & 29.2 & 30 & 25 \\
\hline 1-5 years & 108 & 46.3 & 58 & 48.3 \\
\hline 5-10 years & 34 & 14.6 & 23 & 19.2 \\
\hline$>10$ years & 23 & 9.9 & 9 & 7.5 \\
\hline \multicolumn{5}{|l|}{ Interruption of HAART } \\
\hline Yes & 49 & 21 & 41 & 34.2 \\
\hline No & 184 & 79 & 79 & 65.8 \\
\hline \multicolumn{5}{|l|}{$\mathrm{CD}^{+}{ }^{+}$count $^{\mathrm{b}}$} \\
\hline$<100$ & 10 & 4.2 & 11 & 8.7 \\
\hline $101-500$ & 117 & 49.2 & 62 & 49.2 \\
\hline $501-1,000$ & 91 & 38.2 & 43 & 34.1 \\
\hline$>1,000$ & 20 & 8.4 & 10 & 8 \\
\hline \multicolumn{5}{|l|}{ HIV viral load ${ }^{b}$} \\
\hline Undetectable $(<40)$ & 101 & 42.4 & 45 & 35.7 \\
\hline $40-500$ & 63 & 26.5 & 30 & 23.8 \\
\hline $501-10,000$ & 34 & 14.3 & 21 & 16.7 \\
\hline$>10,000$ & 40 & 16.8 & 30 & 23.8 \\
\hline Total & 238 & 100 & 126 & 100 \\
\hline
\end{tabular}

${ }^{a}$ Monthly family income in multiples of minimum Brazilian wage (equivalent to 252 USD) at time of data collection. ${ }^{\mathrm{b}}$ Results are referred to the last test count before data collection Abbreviations: PLWHA, people living with HIV/AIDS; HAART, highly active antiretroviral therapy. 
Table.2 HIV-associated comorbidities in PLWHA in Belém, northern Brazil

\begin{tabular}{|l|c|c|c|c|}
\hline \multirow{2}{*}{ HIV-associated comorbidity } & \multicolumn{2}{|c|}{ Male } & \multicolumn{2}{c|}{ Female } \\
\hline Syphilis & $\mathbf{n}$ & $\mathbf{( \% )}$ & $\mathbf{n}$ & $\mathbf{( \% )}$ \\
\hline Tuberculosis & 44 & 26.7 & 13 & 16.9 \\
\hline Neurotoxoplasmosis & 38 & 23 & 22 & 28.6 \\
\hline Viral hepatitis & 36 & 21.8 & 16 & 20.8 \\
\hline Diabetes & 24 & 14.6 & 5 & 6.5 \\
\hline Stroke & 4 & 2.4 & 5 & 6.5 \\
\hline Hypertension & 3 & 1.8 & 6 & 7.8 \\
\hline Others & 1 & 0.6 & 2 & 2.6 \\
\hline \multicolumn{1}{|c|}{ Total } & 15 & 9.1 & 8 & 10.3 \\
\hline
\end{tabular}

Table.3 Psychosocial characteristics and functional independence measures in PLWHA in Belém, northern Brazil

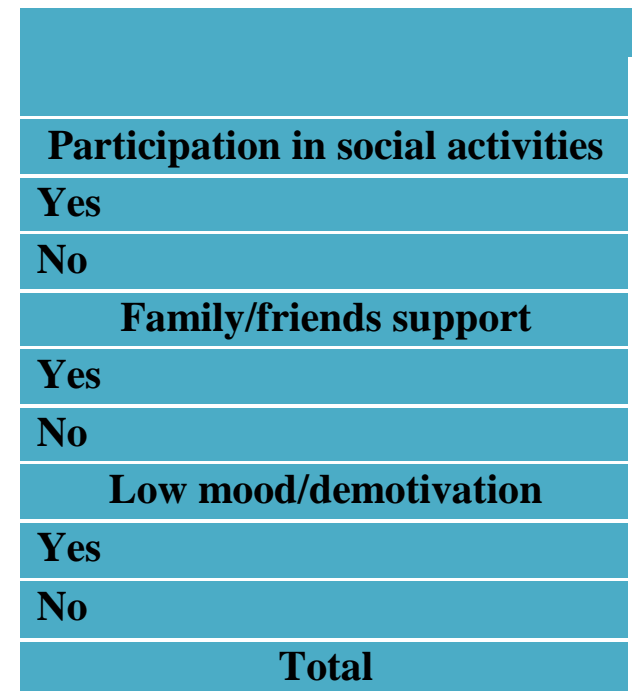

\begin{tabular}{|c|c|c|c|c|}
\hline \multicolumn{2}{|c|}{ Male } & \multicolumn{2}{c|}{ Female } & $p^{\mathrm{a}}$ \\
\hline $\mathbf{n}$ & $\mathbf{( \% )}$ & $\mathbf{n}$ & $\mathbf{( \% )}$ & \\
\hline 168 & 70.6 & 92 & 73 & 0.7145 \\
\hline 70 & 29.4 & 34 & 27 & \\
\hline & & & & \\
\hline 199 & 83.6 & 105 & 83.3 & 0.9363 \\
\hline 39 & 16.4 & 21 & 16.7 & \\
\hline & & & & \\
\hline 57 & 24 & 48 & 38.1 & 0.0067 \\
\hline 181 & 76 & 78 & 61.9 & \\
\hline $\mathbf{2 3 8}$ & $\mathbf{1 0 0}$ & $\mathbf{1 2 6}$ & $\mathbf{1 0 0}$ & \\
\hline
\end{tabular}

${ }^{a}$ Chi-squared test

Table.4 Functional independence measures of PLWHA in Belém, northern Brazil

\begin{tabular}{|l|}
\multicolumn{1}{|c|}{ Independence level } \\
\hline Independent \\
\hline Semi-dependent (moderate dependence) \\
\hline Dependent (fully dependent) \\
\hline Total
\end{tabular}

\begin{tabular}{|c|c|c|c|}
\hline \multicolumn{2}{|c|}{ Male } & \multicolumn{2}{c|}{ Female } \\
\hline n & $(\%)$ & n & $(\%)$ \\
\hline 212 & 89.1 & 106 & 84.1 \\
\hline 24 & 10.1 & 19 & 15.1 \\
\hline 2 & 0.8 & 1 & 0.8 \\
\hline $\mathbf{2 3 8}$ & $\mathbf{1 0 0}$ & $\mathbf{1 2 6}$ & $\mathbf{1 0 0}$ \\
\hline
\end{tabular}


Table.5 Comparison between functional independence status and clinical parameters in PLWHA in Belém, northern Brazil

\begin{tabular}{|c|c|c|c|c|c|}
\hline & \multicolumn{2}{|c|}{ Independent } & \multicolumn{2}{|c|}{ Dependent $^{\mathrm{a}}$} & \multirow[t]{2}{*}{$\mathbf{p}^{b}$} \\
\hline & $\mathbf{n}$ & $(\%)$ & $\mathbf{n}$ & $(\%)$ & \\
\hline \multicolumn{6}{|c|}{ HIV-associated comorbidities } \\
\hline none & 172 & 95.6 & 8 & 4.4 & \multirow[t]{4}{*}{$<0.0001$} \\
\hline 1 & 117 & 86.0 & 19 & 14.0 & \\
\hline 2 & 24 & 66.7 & 12 & 33.3 & \\
\hline$>2$ & 5 & 41.7 & 7 & 58.3 & \\
\hline \multicolumn{6}{|c|}{ Duration of HIV infection } \\
\hline$<1$ year & 128 & 94.1 & 8 & 5.9 & \multirow[t]{4}{*}{0.0167} \\
\hline $1-5$ years & 109 & 83.2 & 22 & 16.8 & \\
\hline 5-10 years & 56 & 86.2 & 9 & 13.8 & \\
\hline$>10$ years & 25 & 78.1 & 7 & 21.9 & \\
\hline \multicolumn{6}{|c|}{$\mathrm{CD} 4^{+}$count $^{\mathrm{c}}$} \\
\hline$<100$ & 14 & 66.7 & 7 & 33.3 & \multirow[t]{4}{*}{0.0076} \\
\hline $101-500$ & 155 & 86.6 & 24 & 13.4 & \\
\hline $501-1,000$ & 124 & 92.5 & 10 & 7.5 & \\
\hline$>1,000$ & 25 & 83.3 & 5 & 16.7 & \\
\hline \multicolumn{6}{|c|}{ HIV viral load ${ }^{\mathrm{c}}$} \\
\hline Undetectable $(<40)$ & 163 & 87.2 & 24 & 12.8 & \multirow[t]{4}{*}{0.748} \\
\hline $40-500$ & 47 & 90.4 & 5 & 9.6 & \\
\hline $501-10,000$ & 46 & 83.6 & 9 & 16.4 & \\
\hline$>10,000$ & 62 & 88.6 & 8 & 11.4 & \\
\hline
\end{tabular}

The present study is pioneer in evaluating this information in northern Brazil and also to investigate the functional capacity for ADL in PLWHA according to an already wellestablished protocol [Pretz et al., 2016]. Furthermore, we analyzed the consequences of HIV-associated disability and its effects in patients' quality of live.

Our results showed a low prevalence of individuals with functional dependence. Most individuals considered themselves as independent $(87.4 \%)$, which seems to be high compared to other studies that reported an independence level varying from 9.76 to 14.51 on a scale range from 4 to 20 [Bayisa and Wubshet, 2016; Passos and Souza, 2015; Hipolito et al., 2017]. These authors used the World Health Organization Quality of Life Instrument, brief version (WHOQOLHIV Bref) [Bayisa and Wubshet, 2016; Passos and Souza, 2015; Hipolito et al., 2017]. In our study, $11.8 \%$ were considered semi-dependent and only $0.8 \%$ fully dependent. Educational background seems to play a role in physical and psychological ways that shape the way that PLWHA face the disease, which in turn affects the level of independence and the QoL. In this study $23.9 \%$ of male and $8.7 \%$ of female had access to higher education, and not surprisingly, women suffered more than men from low 
$\operatorname{mood} /$ demotivation. The elevated level of independence observed in our study may be due to the high prevalence of participants who attended a higher education course (overall $18.7 \%$ ), which is between around 1.5 to 2 times higher than what was found in other studies with 9.8\% [Passos and Souza, 2015] and 12.1 [Bayisa and Wubshet, 2016]. Some studies have reported that PLWHA have difficulty to get or maintain their employment; they experience elevated levels of stress, which reflects negatively in the quality of lives of these individuals [Benedict et al., 2000; Blackstone et al., 2012; Ferreira et al., 2012; Kamat et al., 2013].

Interestingly, this study found that mostly of PLWHA are engaged in social activities and had the support of friends and/or family members to do so. Keeping an active social life and a good social interaction with family and friends are key factors to deal with all the challenges associated with the disease itself and for keeping the adherence to the antiretroviral treatment. On the other hand, lack of this support is associated with a higher likelihood to abandon the treatment or leading to social exclusion, thereby acceleration the patients' functional decline [Ferreira et al., 2012; Kamat et al., 2013]. In this study, most subjects reported never having abandoned the HAART, which may reflect in a better QoL.

Despite the advances in HIV therapy, HIVassociated comorbidities are still common in PLWHA and these are the main causes of sequalae and disabilities experienced by these individuals [Zingmond et al., 2017]. Most of participants in this study, regardless of gender, have experienced some sort of HIVassociated comorbidity, which was linked to functional decline. However, only $12.6 \%$ of the participants were classified as dependent or semi-dependent that required some type of assistance. Functional dependence was linked with HIV-associated comorbidities, such as syphilis, tuberculosis and neurotoxoplasmosis; duration of HIV infection; and low $\mathrm{CD}^{+}$count [Blackstone et al., 2012; Ferreira et al., 2012; Kamat et al., 2013; Troncoso and Conterno, 2015; Cho et al., 2015].

The main functional disabilities were related to tasks that required physical efforts such as walking, climbing stairs, locomoting and commuting according to the FIM. Even in cases when a patient has achieved the maximum score in the FIM (considered independent), this does not mean that the patient does not have a clinical complaint [Erlandson et al., 2014; Benedict et al., 2000; Blackstone et al., 2012]. However, even facing some difficulties, this patient could perform all the ADL without external aid. The physical impairment in ADL, which are simpler and more meaningful, is related to an overall weaker state.

Preventive measures seem to be important to avoid neurological disabilities and keep PLWHA with a better QoL and longer productive life. Although the techniques used to prevent neurological disability do not alter the natural course of HIV infection, they often increase the functional performance of these individuals. Identifying the problems and disabilities presented by PLWHA is essential for a proper referral to special care, which includes preventive measures, basic external support and rehabilitation services. Early detection of physical and/or functional disabilities is important to ensure a better QoL for these individuals.

Identification of socio-demographic characteristics, functional and independence status of PLWHA are valuable information to establish specific public health policies and they are an efficient way to provide aid to these patients and improve their QoL [Machado et al., 2013]. An early 
identification of any functional disability is fundamental to initiate therapeutic intervention that can minimize further complications and prevent possible sequelae.

In summary, we observed that the independence status of PLWHA on their ADL are related to the presence of HIV-associated comorbidities, duration of HIV infection and $\mathrm{CD} 4^{+}$count.

We observed that the presence HIVassociated comorbidities (combination of 2 or more are even more debilitating) increase the level of individuals' dependence due to motor and neurological disabilities.

Positive and interesting facts found in our study are that most of the participants reported to have an active social life and received family/friends support, they also demonstrated more access to a higher education, which combined may reflect in a better way to face the disease, improve the QoL, and increase the adherence to the antiretroviral therapy.

\section{Acknowledgments}

The authors thank to the Secretaria de Saúde do Município de Belém - Brasil, the diretor board of the Centro de Atendimentoem Doenças Infecciosas Adquiridas (CASADIA), and all participants of this study.

\section{Funding}

This research did not receive any specific grant from funding agencies in the public, commercial, or not-for-profit sectors. The publication of this article was supported by PROPESP/UFPA.

\section{Conflicts of interest}

There are no conflicts of interest.

\section{Ethical approval}

The study was approved by the ethics committee from the Instituto de Ciências da Saúde, Universidade Federal do Pará, under number CAAE 56117616.0.0000.0018.

\section{Informed Consent}

Informed consent was obtained from all individual participants included in the study.

\section{References}

Aydin T, Taspinar O, Kepekci M, Keskin Y, Erten B, Gunel M, et al., 2016. Functional independence measure scores of patients with hemiplegia followed up at home and in university hospitals. J PhysTher Sci. 28(2): 553-7.

Bayisa M, and Wubshet M. 2016. Selfreported physical functioning and factors associated with it among HIV infected adults on antiretroviral treatment at the university of Gondar hospital, Ethiopia. Braz J Med Human Health. 2: 39-48

Benedict RH, Mezhir JJ, Walsh K, Hewitt RG. 2000. Impact of human immunodeficiency virus type-1associated cognitive dysfunction on activities of daily living and quality of life. Arch ClinNeuropsychol. 15(6): 535-44.

Blackstone K, Moore DJ, Heaton RK, Franklin DR, Woods SP, Clifford DB, et al., 2012. Diagnosing symptomatic HIV-associated neurocognitive disorders: self-report versus performance-based assessment of everyday functioning. IntNeuropsychol Soc. 18(1): 79-88.

Carioli J, and Teixeira AR. 2014. Use of hearing AIDS and functional capacity in middle-aged and elderly individuals. Int Arch Otorhinolaryngol. 18(3):249-54. 
Carvour ML, Harms JP, Lynch CF, Mayer RR, Meier JL, Liu D, et al., 2015. Differential Survival for Men and Women with HIV/AIDS-Related Neurologic Diagnoses. PLoS One. 10(6): e0123119.

Cho M, Kim D, Chung J, Park J, You H, Yang Y. 2015. Effects of a cognitiveenhancement group training program on daily living activities, cognition, and depression in the demented elderly. J PhysTher Sci. 27(3): 681-4.

Cobbing S, Hanass-Hancock J, Myezwa H. 2015. A home-based rehabilitation intervention for people living with HIV and disability in a resource-poor community, KwaZulu-Natal: study protocol for a randomised controlled trial. Trials. 16: 491.

Deeks SG. 2011. HIV infection, inflammation, immunosenescence, and aging.AnnuRev Med. 62: 141-55.

DubÈ B, Benton T, Cruess DG, Evans DL. 2005. Neuropsychiatric manifestations of HIV infection and AIDS. J Psychiatry Neurosci. 30(4): 237-46.

Erlandson KM, Schrack JA, Jankowski CM, Brown TT, Campbell TB. 2014. Functional impairment, disability, and frailty in adults aging with HIVinfection. Curr HIV/AIDS Rep. 11(3): 279-90.

Ferreira BE, Oliveira IM, Paniago AM. 2012. Quality of life of people living with HIV/AIDS and its relationship with CD4+ lymphocytes, viral load and time of diagnosis. Rev Bras Epidemiol. 15(1): 75-84.

Heaton RK, Clifford DB, Franklin DR, Woods SP, Ake C, Vaida F, et al., 2010. HIV-associated neurocognitive disorders persist in the era of potent antiretroviral therapy: CHARTER Study. Neurology. 75(23): 2087-96.

Hipolito RL, Oliveira DC, Costa TLD, Marques SC, Pereira ER, Gomes AMT.
2017. Quality of life of people living with HIV/AIDS: temporal, sociodemographic and perceived health relationship. Rev Lat Am Enfermagem. 25: e2874

Huang MB, Ye L, Liang BY, Ning CY, Roth WW, Jiang JJ, et al., 2015. Characterizing the HIV/AIDS Epidemic in the United States and China. Int $\mathrm{J}$ Environ Res Public Health. 13(1): ijerph13010030.

Kamat R, Morgan E, Marcotte TD, Badiee J, Maich I, Cherner M, et al., 2013. Implications of apathy and depression for everyday functioning in HIV/AIDS in Brazil.J Affect Disord. 150(3): 106975.

Machado FN, Machado AN, Soares SM. 2013. Comparison between ability and performance: a study on the functionality of dependent elderly individuals. RevLatAm Enfermagem. 21(6): 1321-9.

Matinella A, Lanzafame M, Bonometti MA, Gajofatto A, Concia E, Vento S, et al., 2015. Neurological complications of HIV infection in pre-HAART and HAART era: a retrospective study. J Neurol. 262(5): 1317-27.

Mayo NE, Brouillette MJ, Fellows LK, Investigators PBHN. 2016. Understanding and optimizing brain health in HIV now: protocol for a longitudinal cohort study with multiple randomized controlled trials. BMC Neurol. 16: 8 .

Passos SM, and Souza LD. 2015. An evaluation of quality of life and its determinants among people living with HIV/AIDS from Southern Brazil.CadSaude Publica. 31(4): 80014.

Pretz CR, Kean J, Heinemann AW, Kozlowski AJ, Bode RK, Gebhardt E. 2016. A Multidimensional Rasch Analysis of the Functional 
Independence Measure Based on the National Institute on Disability, Independent Living, and Rehabilitation Research Traumatic Brain Injury Model Systems National Database. J Neurotrauma. 33(14): 1358-62.

Riberto M, Miyazaki MH, Juca SSH, Sakamoto H, Pinto PPN, Battistella LR. 2004. Validação da versão Brasileira da Medida de Independência Funcional. Acta fisiátrica. 11(2): 72-6.

Tan IL, Smith BR, von Geldern G, Mateen FJ, McArthur JC. 2012. HIV-associated opportunistic infections of the CNS. Lancet Neurol. 11(7): 605-17.

Tedaldi EM, Minniti NL, Fischer T. 2015. HIV-associated neurocognitive disorders: the relationship of HIV infection with physical and social comorbidities. Biomed Res Int. 2015: 641913

Troncoso FT, and Conterno LO. 2015. Prevalence of neurocognitive disorders and depression in a Brazilian HIV population. Rev Soc Bras Med Trop. 48(4): 390-8.

Vanbellingen $\mathrm{T}$, Ottiger B, Pflugshaupt $\mathrm{T}$, Mehrholz J, Bohlhalter S, Nef T, et al., 2016. The Responsiveness of the Lucerne ICF-Based Multidisciplinary Observation Scale: A Comparison with the Functional Independence Measure and the Barthel Index. Front Neurol. 7: 152.

Zingmond DS, Arfer KB, Gildner JL, Leibowitz AA. 2017. The cost of comorbidities in treatment for HIV/AIDS in California. PLoS One. 12(12): e0189392.

\section{How to cite this article:}

Ana Helena de Oliveira Andrade, Sandra Souza Lima, Andre Luis Ribeiro Ribeiro, Sílvio Augusto Fernandes de Menezes and Luiz Fernando Almeida Machado. 2018. Comorbidities and Functional Impairment among People Living With HIV in Belém, Pará, Amazon Region of Brazil. Int.J.Curr.Microbiol.App.Sci. 7(07): 4180-4190. doi: https://doi.org/10.20546/ijcmas.2018.707.488 